\section{Economic geology and tectonics}

Metallogeny and Plate Tectonics. Edited by D. F. Strong. Pp. vii +660 . (Geological Association of Canada: Department of Earth Sciences, University of Waterloo, Waterloo, Ontario, 1976.)

IN some areas, the plate tectonic bandwagon must be approaching its elastic limit as more and more ideas and interpretations are heaped on it, yet surprisingly little attention had previously been paid to corallaries of this model for economic geology and Precambrian tectonics. Major progress in both aspects have now been made with the almost simultaneous publication of the proceedings of two separate NATO conferences-B. F. Windley's The Early History of the Earth (Wiley, 1976) and D. F. Strong's Metallogeny and Plate Tectonics. The latter comprises 26 papers and six abstracts concerned mostly with either general concepts or specific locations, with the main emphasis on attempts to interpret different metallogenies in terms of the current plate tectonic framework. The standard is inevitably variable, but generally very good. The papers are in English, with both English and French abstracts, and it is a credit to the editor that his work on the 'foreign' contributions is undetectable yet must be there for them to flow as well as they do. Similarly the editor must have worked hard to keep out too many pictures of subduction zone models which, although the dominating figure, do not obtrude.

The production is generally good, the only major flaw being that there is no index. This omission is particularly serious for such a heterogeneous collection of papers which, although grouped into sections, contain numerous cases of partial or even complete discussion of features which belong in other sections. This is further aggravated by the order in which the sections are presented: metal deposits in convergent plate margins, intraplate environments, orogenic belts and ores of Precambrian age. This order presumably reflects the fact that orogenic belts contain both subduction and intraplate ore bodies, and Precambrian deposits may contain all forms and also be characterised by modified plate tectonic models resulting from, for example, the much higher average geothermal gradients of Archaean times. Nevertheless, present day subduction zones, such as the Andes and Japan, which form the majority of the areas discussed under convergent zones, also contain pre-existing ore bodies in the same way as the Canadian cordillera, which are discussed under orogenic belts. Such difficulties in grouping the papers would not have mattered so much if the whole volume was indexed, even in a coarse fashion. Under the circumstances, it would have been better to commence with accretion zone deposits, and then have orogenic belts following convergent zones.

Most of the early proponents of metallogeny and plate tectonics have contributed to this publication, but it is significant that the 'grey-beards', in this subject, such as R. H. Sillitoe, must be considered those who published on the subject in or before 1973, and sufficient credit is still not given to those geochemists who determined the zonations in island arc environments well before the discovery of plates. Those papers by E. Horikoshi (northeastern Japan), A. Y. Glikson (Archaean to early Proterozoic Shield structures), T. Sato (green tuff province, Japan), F. J. Sawkins (massive sulphides), R. A. Stacey (Canadian cordillera) and H. S. Swinden and D. F. Strong (Appalachians, North American cordillera, south-eastern Australia) are particularly interesting. Others are disappointing rather than unimportant. For example, that by $P$. Laznicka (lead deposits on global plate model) could have been of major significance, but is marred by dogmatic classification of specific ore depositssuch as the Red Sea as intracontinental rather than an incipient ocean rise, the southern European Permo-Triassic deposits as a trailing

\section{Opisthobranch molluses}

British Opisthobranch Molluscs. (Synopses of the British Fauna, No. 8.) By T. E. Thompson and G. H. Brown. Pp. 203. (Academic: London, New York and San Francisco, 1976.) £3.50.

This is a very welcome addition to the recent series of Synopses of the British Fauna. The book is well designed and attractive to look at. There is less restriction on size than in previous numbers and this has enabled the authors to have, for most species, a large drawing occupying one page and on the opposite page a brief but adequate description of external features necessary for identification, notes on biology and worldwide distribution. Technical terms have been kept to a minimum and the introductory pages and descriptions are designed to cater for the non-professional zoologist.

The complementary talents of both authors are well exhibited. Gregory H. Brown's drawings set forth the edge, and so forth. This may all be correct but is certainly arguable, yet the final conclusions are quoted to $0.01 \%$; and one major environment, with $37.69 \%$ of world reserves, occurs in trailing margins - an environment which seems to be defined as one into which sedimentary ores are placed together with those which are not obviously in any other category. The conclusion should be that some one-third of the world's lead occurs in sedimentary forms of uncertain origin.

The general lack of consideration of sedimentary ores is understandable, although disappointing. There is evidence that most of these have been strongly influenced by palaeoclimatic conditions and hence palaeolatitude. As this is determined by the motions of the plates, these ores are as related to plate tectonic motions as subduction zone metals. Other gaps, however, include kimberlites, which are not merely important economically but have major implications for upper mantle evolution. Nevertheless this publication is obviously essential to even the smallest geological library. The hope is now that some future NATO conference will turn to consider energy resources in the same context. The seafloor conveyor still has some way to go before all of the ideas have been sweated out of its subducting melange! D. H. Tarling

D. H. Tarling is a Senior Lecturer in the Department of Geophysics and Planetary Physics at the University of Newcastle upon Tyne, UK.

salient features of each species and the life-like posture. T. E. Thompson, a well known specialist on opisthobranchs and an aqualung enthusiast, is familiar with the habitats of many species and has examined nearly all the 135 which are described. When opisthobranchs have to be identified it is now no longer necessary to search the classical works and paraphrase the language of nearly 150 years ago. In this synopsis concise keys lead to family and species. Ideally such attractive molluscs would be depicted in colour, but the cost is prohibitive. The single plate that is provided, although valuable in displaying their beauty of form, whets the appetite for more.

In such a detailed compilation it is difficult to prevent a few misconceptions: the eyes of Stiliger bellulus are lacking in the description and the figure; the dorsal surface of Limapontia capitata is figured with a pale cross, but this is of rare occurrence.

V. Fretter

$V$. Fretter is a former Reader in the Department of Zoology at the University of Reading, UK. 